\title{
Validity Evidences of the Inventory of Personality Organization - Brasil (IPO-Br): Its Relation with the Five-Factor Model of Personality
}

\author{
Liége Barbieri Silveira*,1 \\ Orcid.org/0000-0003-1948-928 \\ Sérgio Eduardo Silva de Oliveira ${ }^{2}$ \\ Orcid.org/0000-0003-2109-4862 \\ Denise Ruschel Bandeira ${ }^{3}$ \\ Orcid.org/0000-0001-9867-2718 \\ ${ }^{1}$ Universidade Federal da Fronteira do Sul, Erechim, RS, Brasil \\ ${ }^{2}$ Universidade de Brasília, Brasília, DF, Brasil \\ ${ }^{3}$ Universidade Federal do Rio Grande do Sul, Porto Alegre, Brasil
}

\begin{abstract}
The aim of the present study was to investigate evidences of convergent and incremental validity for the Brazilian version of the Inventory of Personality Organization (IPO-Br), an instrument that evaluates pathological functioning of personality. The sample included 170 individuals of which $61.2 \%$ were patients attending psychiatric or psychological treatment. The average difference for clinical and nonclinical groups were compared, and correlational and multivariate analyses were performed between the IPO-Br and of the Bateria Fatorial da Personalidade, a Brazilian measure of the Five-Factor Model (FFM). Moderate to high positive correlations were found between the IPO-Br factors and the Neuroticism dimension. In addition, the FFM explained between 27 and $68 \%$ of the variance of the IPO-Br factors. The IPO-Br was also able to differentiate people with and without psychopathological indicators, as well as capable to increment the explanation of psychiatric severity beyond the explanation given by the FFM, indicating adequate evidences of validity and clinical utility of the IPO-Br.
\end{abstract}

Keywords: Personality, pathology of personality, Five-Factor Model, evidences of validity.

* Mailing address: Universidade Federal da Fronteira Sul, Campus Erechim, ERS 135 - Km 72, 200, Zona Rural, Erechim, RS, Brazil 99700-970. Caixa Postal 764. Phone: (54) 33217-066. E-mail: liegebsilveira@gmail.com Acknowledgment: The authors are grateful for the financial support of the following funding agencies: CAPES, through the granting of a doctoral scholarship to SESO; and CNPq, for granting scholarship productivity to DRB and by the Public Announcement of MCTI/CNPq/MEC/CAPES Nº 18/2012 grants. 


\section{Evidências de Validade do Inventário de Organização da Personalidade - Brasil (IPO-Br): Relação com o Modelo dos Cinco Grandes Fatores da Personalidade}

\section{Resumo}

O objetivo deste trabalho foi investigar evidências de validade convergente e incremental da versão brasileira do Inventário de Organização da Personalidade (IPO-Br), sendo este um instrumento que avalia o funcionamento patológico da personalidade. Participaram do estudo 170 indivíduos, sendo 61,2\% pacientes em atendimento psiquiátrico ou psicológico. Comparou-se a diferença das médias dos grupos clínico e não-clínico. Foram realizadas também análises correlacionais e multivariadas entre o IPO-Br e as dimensões da Bateria Fatorial da Personalidade (BFP), baseada no modelo dos Cinco Grandes Fatores de Personalidade. Foram encontradas correlações positivas, moderadas a altas, entre os fatores do IPO-Br com o fator Neuroticismo. Além disso, as facetas da BFP explicaram entre 27 a $68 \%$ da variância dos fatores do IPO-Br. O IPO-Br também mostrou-se capaz de diferenciar pessoas com e sem indicadores psicopatológicos, assim como de incrementar explicação para a severidade dos sintomas psiquiátricos para além da explicação dada pelos fatores da BFP, indicando adequadas evidências de validade e utilidade clínica do IPO-Br.

Palavras-chave: Personalidade, patologia da personalidade, Modelo dos Cinco Grandes Fatores, evidências de validade.

\section{Evidencias de Validez del Inventario de Organización de la Personalidad - Brasil (IPO-Br): Relación con el Modelo de los Cinco Grandes Factores de la Personalidad}

\section{Resumen}

El presente estudio investigó evidencias de validez convergente e incremental de la versión brasileña del Inventario de Organización de la Personalidad (IPO-Br), un instrumento que evalúa el funcionamiento patológico de la personalidad. Participaron 170 personas, siendo el $61,2 \%$ pacientes en tratamiento psiquiátrico o psicológico. Se compararon las medias de las diferencias en los grupos clínicos y no clínicos, y se realizaron análisis de correlación y multivariado entre el IPO-Br y la Bateria Fatorial da Personalidade (BFP). Se encontraron correlaciones, positivas moderadas a altas entre los factores del IPO-Br con Neuroticismo. Además, las facetas de BFP explicaron entre el 27-68\% de la varianza de los factores del IPO-Br. El IPO-Br también demostró ser capaz de diferenciar personas con y sin indicadores psicopatológicos y de incrementar la explicación para la severidad psiquiátrica de la personalidad más allá de la explicación dada por el BFP, lo que indica una evidencia adecuada de la validez y la utilidad clínica del IPO-Br.

Palabras clave: Personalidad, patología de la personalidade, Cinco Grandes Factores de la Personalidad, evidencias de validez.

Personality can be defined as a dynamic integration of the totality of subjective experiences and patterns of behavior of a person. Thus, it represents a much more complex and sophisticated entity than a simple sum of characteristics and traits (Kernberg, 2016), driving studies in different times and cultures (Millon, 2012).

Dozens of approaches have been devoted to the study of normal and pathological personality in the last century. Among the most relevant 
are the psychodynamic approach and trait theory, which were used in this study due to the important contributions they offer for the understanding of the pathological functioning of the personality. The psychodynamic approach is one of the more widespread and most used in clinical practice and was the one that used the concept of personality disorder for the first time. On the other hand, trait theory is an empirically based approach with solid foundations in the study of normal personality, that having been extending to examine personality pathologies in the last decades (Heim \& Westen, 2009).

\section{Psychodynamic Perspective}

From a psychodynamic point of view, one of the most important characteristics of personality disorders is related to the fact that they represent constellations of psychological processes rather than distinct symptoms. In addition, these disorders are located on a continuum that ranges from healthy to pathological functioning of the personality, reflecting deeply rooted and changeresistant processes (Heim \& Westen, 2009).

One of the most commonly used theories covering these principles is the structural theory of personality developed by Otto F. Kernberg (Heim \& Westen, 2009). This model proposes the existence of structural organizations responsible for the mental functioning. They are established from a continuum and arranged according to the dominant characteristics of the patient in relation to the degree of the identity integration, to the types of defensive operations that he/she habitually uses and to his/her ability to test reality (Kernberg \& Caligor, 2005).

The Inventory of Personality Organization (IPO) was developed based on the model proposed by Kernberg. This self-report instrument evaluates pathological dimensions of the personality and is used to formulate structural diagnoses. The instrument was constructed to cover five personality dimensions, with the first three constituting the Primary Clinical Scales, being designed to assess the degree of identity pathology (Identity Diffusion - ID), the level of the immature defensive mechanisms (Primitive
Defenses - PD) and the degree of impairment in the ability to test reality (Reality Testing - RT). The other two dimensions, grouped in the socalled Additional Scales, seek to estimate the level of aggression directed against oneself and against others (Aggression - Ag) and the degree of impairment in the formation of moral and ethical values (Moral Values - MV; Clarkin, Foelsch, \& Kernberg, 2001; Ruiz \& Sanchez, 2008). However, recent empirical studies on the data covariance matrix have indicated a factorial solution distinct from that theoretically established (Ellison \& Levy, 2012; Oliveira, 2016; Preti et al., 2015). The Primary Clinical Scales have presented a four factor rather than three factor structure (Ellison \& Levy, 2012; Oliveira, 2016; Preti et al., 2015), with the domains denominated Instability of Self/Others (ISO), Instability of Goals (IG), Instability of Behavior (IB) and Psychosis (PSI). These factors are intrinsically related to the theoretical proposal of Kernberg (1995), where the ISO and IG domains are components of the identity diffusion syndrome. The IB domain reflects the impulsive and erratic characteristics of the Borderline Personality Organization. Finally, the PSI factor consisted of items that reflect sensory-perceptual changes, which are the central aspects of the Psychotic Personality Organization. Regarding the Additional Scales, Oliveira (2016) found a three factor solution instead of two, where the Aggression factor was divided into Self-Directed Aggression (SDA) and Sadistic Aggression (SA), with the Moral Values factor being practically the same, even though it is called the Distortion of Moral Values (DMV) to represent the maladaptive level of this dimension.

The IPO (Lenzenweger, Clarkin, Kernberg, \& Foelsch, 2001) has been translated and adapted to different languages, with all versions presenting adequate psychometric properties in countries such as Canada (Normandin et al., 2002), Colombia (Ruiz \& Sánchez, 2008), Japan (Igarashi et al., 2009), Netherlands (Berghuis, Kamphuis, Boedijn, \& Verheul, 2009), Belgium (Lowyck, Luyten, Verhaest, Vandeneede, \& 
Vermote, 2013; Smits, Vermote, Claes, \& Vertommen, 2009), Germany (Zimmermann et al., 2013) and Italy (Preti et al., 2015), among others. In addition, studies have demonstrated convergent validity of the instrument with several psychological constructs, such as depression, anxiety, psychotic symptoms, fragile self-control, and low marital satisfaction (Caligor, Kernberg, \& Clarkin, 2007; Critchfield, Levy, Clarkin, \& Kernberg, 2008; Smits et al., 2009; Verreault, Sabourin, Lussier, Normandin, $\&$ Clarkin, 2013). The IPO was also useful in studies that investigated the quality of the bond between mothers and their children; one indicated an association between identity diffusion and low sensitivity of mothers in their interaction with their children (Ensink, Rousseau, Biberdzic, Bégin, \& Normardin, 2017) and another one showed the impact of the mothers' level of identity diffusion over the externalizing behaviors presented by their children (Goodman, Bartlett, \& Stroh, 2013).

In Brazil, the instrument was translated and adapted by Oliveira and Bandeira (2011), and psychometric investigations were carried out with a community sample (Oliveira, 2012) and with clinical and non-clinical samples (Oliveira, 2016). In the adaptation and validation studies for Brazil, there was evidence of convergent and concurrent validity with measures of adaptive and maladaptive psychological states and functions and with general health criteria. However, no studies were performed comparing the IPO$\mathrm{Br}$ to another personality instrument.

\section{Trait Theory}

The second perspective to be discussed in this study is trait theory, which is an approach that stands out in the study of personality due to the great number of empirical studies, especially related to the Five-Factor Model (FFM; Heim $\&$ Westen, 2009). This model, in its present formulation, describes the personality in a simple and comprehensive way, through the proposition of the traits of Extroversion, Neuroticism, Conscientiousness, Agreeableness and Openness (Costa \& Widiger, 2002). In addition, this model refers to the more prominent contemporary traits theory, whereby personality disorders are not considered entities distinct from the normal personality, but rather as an extreme expression of the poles of these traits (Heim \& Westen, 2009). Studies have shown that high scores in Neuroticism combined with low scores in Agreeableness and Conscientiousness are strongly linked to severe personality pathologies (Berghuis et al., 2009; Costa \& Widiger, 2002; Laverdière et al., 2007; Quilty, Ayearst, Chmielewski, Pollock, \& Bagby, 2013; Saulsman \& Page, 2004; Widiger, Trull, Clarkin, Sanderson, \& Costa, 2002). Some authors also report that low Extroversion may be associated with these pathologies (Malouff, Thorsteinsson, \& Schutte, 2005).

\section{The Current Study}

Considering the fact that studies investigating the relationship between the IPO-Br factors and another personality instrument were not found in Brazilian literature, and based on previous studies that present the relationship of the FFM with personality pathology, the present study aimed to investigate evidence of convergent and incremental validity of the IPO-Br with the Bateria Fatorial da Personalidade (BFP [Factorial Personality Battery]; Nunes, Hutz, \& Nunes, 2010). The BFP is an instrument that was developed in Brazil, considering the cultural and linguistic aspects of the country, which evaluates the personality through the FFM.

Our convergent validity hypothesis is to find positive correlations between the IPO-Br factors and Neuroticism, and negative correlations with Agreeableness and Conscientiousness, as previous results reported on Berghuis et al. (2009) study. Regarding the incremental validity, it is expected that the IPO-Br factors will predict the level of common mental disorder over and above the BFP factors.

\section{Method}

\section{Participants}

The sample consisted of 170 individuals (age range from 17 to 73 years, $M=34.4, S D=$ 12.6). The majority of the participants were female $(59.4 \%)$, white $(80 \%)$, with socioeconomic 
level between 1 and 5 minimum wages (68.1\%) and complete or incomplete higher education (51.7\%). Among the participants, $61.2 \%$ were patients who were in psychotherapeutic and/or psychiatric treatment, composing the clinical group. The psychiatric diagnosis of these patients was not considered in this study, but rather the structural diagnosis performed by their clinicians based on a dimensional evaluation proposed by Kernberg (1995) regarding the diffusion of identity, the defense mechanisms most commonly used and the ability to test reality. Therefore, the sample was composed of patients structurally organized from different levels of impairment in the functioning of the personality, from mild to more severe impairment.

\section{Instruments}

Socio-demographic questionnaire: a questionnaire prepared by the authors to characterize the sample, investigating clinical and sociodemographic data.

Inventory of Personality Organization - Brazil (IPO-Br; Oliveira \& Bandeira, 2011): adapted from the original version of the IPO (Clarkin et al., 2001). This is a self-report instrument composed of 83 items, which are scored on a five-point Likert-type scale (1 "Never true" - 5 "Always true"). Studies present adequate psychometric properties for the Brazilian version (Oliveira, 2016; Oliveira \& Bandeira, 2011).

Bateria Fatorial da Personalidade (BFP [Factorial Personality Battery]): an instrument that evaluates the personality through the big five-factor model. The BFP is composed of 126 items, with responses on a seven-point Likerttype scale (1 "I absolutely do not identify with the phrase" - 7 "Describes me perfectly"). The items are distributed in 17 facets that comprise five dimensions: Neuroticism, Extroversion, Agreeableness, Conscientiousness and Openness. The BFP presents adequate psychometric properties (Nunes et al., 2010).

Self-Reporting Questionnaire (SRQ20; Harding et al., 1980): this instrument was developed by the World Health Organization for the screening of common mental disorders in primary care services. The Brazilian version has 20 questions indicative of non-psychotic disorders rated as 'yes' or 'no', with each positive answer equaling one point and the total possible score ranging from 0 to 20 points. The cut-off point established for determining the presence of common mental disorders is 8 points for men and women (Gonçalves, Stein, \& Kapczinski, 2008).

\section{Procedures}

Data collection. The non-clinical sample included students from the Youth and Adult Education (Ensino de Jovens e Adultos - EJA) program and from higher education institutions. The application was carried out collectively and the instruments were delivered in a random order to the participants to avoid response bias due to fatigue. For the administration of the study protocols with the participants of the clinical sample, different strategies were used, according to the site where the data were collected. The administration procedure in the psychological treatment clinics, school-clinics of the universities and mental health outpatient clinics was carried out with the collaboration of the clinician (psychology professional or final year undergraduate trainee), who invited their patients to respond to the instruments. The clinicians underwent brief training so that they could choose patients to participate in the study that presented a certain profile with the possibility of being classified within the structural model of personality proposed by Kernberg (1995). In addition, they chose patients who they thought had the physical and psychological conditions to participate. In some specific cases in which the patient had a more serious pathology and/or low level of education, there was the need for the clinician to assist the patient in completing the protocols for not compromise the answers. However, it is important to note that the professional's assistance focused on the procedure for completing the protocol and not on the choice of answers. With the patients of the Psychosocial Care Centers (Centros de Atenção Psicossocial - CAPS) and inpatient clinics, the entire application was performed by one 
of the study researchers, considering the degree of compromise of the patients for the individual filling of the form.

Data analysis. The data were analyzed using the Statistical Package for the Social Sciences (SPSS, v.17.0). Initially descriptive analyses of the instruments used in the study were made. Analysis of the normality was performed through the Kolmogorov-Smirnov (K-S) test to select the statistical tests to be used. Normality was confirmed for the majority of the scales and, therefore, parametric statistical tests were used.

To verify the need for control variables, Pearson correlations were performed between the ages of the participants and the variables of interest, as well as verification of the differences between the sexes through the t-test. No significant correlations were found with age and, in relation to sex, there was no statistically significant difference for any of the IPO-Br or BFP dimensions, except for the Extroversion factor and for the SRQ-20 total score. As these were the only two variables that presented a difference for sex, it was chosen to carry out the analyses with the total group.

The internal consistency of the instrument scales was analyzed using Cronbach's Alpha. This coefficient varies from 0 to 1 , being classified as very good ( $>.90)$, good (between .80 and .90 ), reasonable (from .70 to .80), weak (from .60 to .70$)$ and inadmissible $(<.60$; Pestana $\&$ Gagueiro, 2014). Effect sizes were calculated and classified using Cohen's $d$, with: $d>0.3$ small, $d>0.5$ moderate, $d>0.8$ large (Cohen, Cohen, West, \& Aiken, 2003).

In order to investigate the convergent validity of the IPO, correlational and multiple regression analyses were performed. Firstly, Pearson correlation analyses were used between the five dimensions of the BFP and the factors of the IPO-Br. The effects sizes of the correlation coefficients were interpreted according to Pestana and Gagueiro (2014), with $r$ of 0.0 to 0.3 very weak; from 0.3 to 0.5 weak; 0.5 to 0.7 moderate; 0.7 to 0.9 strong; and from 0.9 to 1.0 very strong.

In addition, multiple linear regression analyses were conducted, having the facets of the BFP as independent variables and each of the factors of the IPO-Br individually as the dependent variable. According to Hair, Black, Babin, Anderson, and Tatham (2009), the method of predictor selection is used when the aim is to maximize the prediction of the model using the smallest number of possible variables. Considering that this study used an exploratory model, the aim of which was to observe the relationships of possible predictors that are usually neglected, the enter method was chosen.

To investigate the incremental validity of the IPO-Br, hierarchical linear regressions were performed (Dancey \& Reidi, 2013). In the first analysis, the BFP dimensions were placed in the first block and the IPO factors in the second, to verify whether the IPO factors provided additional information for the prediction of psychopathological symptoms (measured by the SRQ20) over and above the factors of the BFP.

Ethical procedures. This study was approved by the research ethics committee of the Institute of Psychology of the Federal University of Rio Grande do Sul, following resolution No. 466 of the National Health Council of December 12, 2012 (Platforma Brasil: CAAE 31610114.9.0000.5334). All study participants voluntarily agreed to participate in the study.

\section{Results}

Table 1 shows the means of the scales for clinical and nonclinical groups and the effect size of the differences. The internal consistency coefficients are also presented, which were considered satisfactory for the majority of the instrument dimensions.

The results showed that the majority of the factors of the IPO-Br discriminated the clinical and nonclinical groups with moderate or large effect sizes. Among the BFP factors, only the Neuroticism and Agreeableness factors presented a significant effect in the discrimination of the groups. Regarding the SRQ-20, the amount of psychopathological symptoms was significantly higher in the clinical group, with a large effect size. 
Table 1

Descriptive Statistics of the Instruments Per Group, Effect Sizes of the Differences between Groups and Internal Consistency Coefficients

\begin{tabular}{|c|c|c|c|c|c|c|c|}
\hline & \multirow{2}{*}{$\begin{array}{l}\text { No. of } \\
\text { items }\end{array}$} & \multirow{2}{*}{$\frac{\text { Non-clinical }}{M(S D)}$} & \multirow{2}{*}{$\frac{\text { Clinical }}{M(S D)}$} & \multirow{2}{*}{$d$} & \multirow{2}{*}{$\frac{d 95 \% \mathrm{CI}}{\text { Low } \mid \mathrm{Upp}}$} & \multirow{2}{*}{$\frac{\text { Total }}{M(S D)}$} & \multirow{2}{*}{$\boldsymbol{\alpha}$} \\
\hline & & & & & & & \\
\hline \multicolumn{8}{|l|}{ IPO-Br } \\
\hline Instability of the Self and Others & 30 & $2.06(0.62)$ & $2.71(0.80)$ & 0.91 & $0.56 \mid 1.21$ & $2.46(0.80)$ & 0.94 \\
\hline Instability of Behavior & 15 & $1.89(0.60)$ & $2.33(0.77)$ & 0.64 & $0.31 \mid 0.94$ & $2.16(0.73)$ & 0.87 \\
\hline Instability of Goals & 02 & $1.88(0.88)$ & $2.50(1.19)$ & 0.59 & $0.26 \mid 0.89$ & $2.26(1.12)$ & 0.77 \\
\hline Psychosis & 10 & $1.49(0.40)$ & $2.03(0.95)$ & 0.74 & $0.37 \mid 1.01$ & $1.82(0.83)$ & 0.88 \\
\hline Self-Directed Aggression & 08 & $1.39(0.26)$ & $1.77(0.76)$ & 0.66 & $0.30 \mid 0.93$ & $1.62(0.64)$ & 0.73 \\
\hline Distortion of Moral Values & 10 & $2.05(0.57)$ & $2.23(0.65)$ & 0.29 & $-0.02 \mid 0.60$ & $2.16(0.62)$ & 0.72 \\
\hline Sadistic Aggression & 07 & $1.19(0.33)$ & $1.32(0.46)$ & 0.32 & $0.00 \mid 0.62$ & $1.27(0.41)$ & 0.74 \\
\hline \multicolumn{8}{|l|}{ BFP } \\
\hline Neuroticism & 29 & $3.10(0.93)$ & $4.18(1.08)$ & 1.07 & $0.73 \mid 1.38$ & $3.76(1.15)$ & 0.92 \\
\hline Agreeableness & 28 & $5.44(0.54)$ & $5.19(0.74)$ & -0.39 & $-0.68 \mid-0.06$ & $5.29(0.68)$ & 0.79 \\
\hline Conscientiousness & 21 & $4.82(0.63)$ & $4.74(0.98)$ & -0.10 & $-0.40 \mid 0.22$ & $4.77(0.86)$ & 0.82 \\
\hline Extroversion & 25 & $4.09(0.81)$ & $3.91(1.08)$ & -0.19 & $-0.49 \mid 0.13$ & $3.99(0.99)$ & 0.88 \\
\hline Openness & 23 & $4.27(0.66)$ & $4.22(0.74)$ & -0.07 & $-0.38 \mid 0.24$ & $4.25(0.72)$ & 0.68 \\
\hline \multicolumn{8}{|l|}{ SRQ-20 } \\
\hline Level of Psychopathology & 20 & $3.58(3.19)$ & $8.90(5.02)$ & 1.26 & $0.87 \mid 1.54$ & $6.58(5.05)$ & 0.88 \\
\hline
\end{tabular}

Note. Differences with no statistical significance $(p>.05)$ presented Cohen $d$ values lower than $|0.30|$.

\section{Convergent Validity}

To verify the convergent validity, correlations between the factors of the IPO-Br and the BFP were estimated, as presented in Table 2. Positive, weak to strong correlations were found between all the factors of the IPO-Br with Neuroticism. Negative correlations of weak to moderate magnitude were also observed with Agreeableness and weak negative, however, significant correlations with Conscientiousness. Negative correlations of weak magnitude or without statistical significance were observed with Extroversion and Openness.

To further understand the relationship between the constructs studied in the bivariate analyses, multiple linear regression analyses were conducted using the BFP facets as the independent variables. For the selection of the facets that would enter the regression analysis, correlation analyses were performed with the IPO-Br factors. Only those facets that presented correlations of $p \leq .25$, according to the criteria of Hosmer, Lemeshow and Sturdivant (2013), were selected. Table 3 presents the results of the regressions.

The facets of the BFP explained more than $42 \%$ of the variance of the IPO-Br factors, except for the IG factor, which had around $27 \%$ of its variance explained. The Vulnerability $(\beta$ $=0.28)$, Depression $(\beta=0.28)$, Competence $(\beta=-0.22)$, Engagement $(\beta=0.18)$, Pride $(\beta=$ $0.14)$, Trust in People $(\beta=-0.13)$ and Weighting $(\beta=-0.12)$ facets contributed in a statistically significant way to the explanation of the variance of the scores of the ISO factor. Regarding the IB factor, it was observed that the Instability $(\beta=$ $0.22)$, Depression $(\beta=0.19)$, Vulnerability $(\beta=$ $0.19)$, Pro-sociability $(\beta=-0.18)$ and Weighting 
Table 2

Correlations between the IPO-Br Factors and the BFP Dimensions

\begin{tabular}{lccccccc}
\hline & ISO & IB & IG & PSI & SDA & DMV & SA \\
\hline Neuroticism & $0.75^{* *}$ & $0.64^{* *}$ & $0.37^{* *}$ & $0.50^{* *}$ & $0.44^{* *}$ & $0.54^{* *}$ & $0.43^{* *}$ \\
Agreeableness & $-0.46^{* *}$ & $-0.55^{* *}$ & -0.15 & $-0.41^{* *}$ & $-0.47^{* *}$ & $-0.53^{* *}$ & $-0.54^{* *}$ \\
Conscientiousness & $-0.23^{* *}$ & $-0.26^{* *}$ & -0.02 & $-0.27^{* *}$ & $-0.36^{* *}$ & $-0.26^{* *}$ & $-0.24^{* *}$ \\
Extroversion & -0.14 & -0.12 & 0.06 & -0.10 & -0.09 & $-0.20^{*}$ & 0.00 \\
Openness & -0.04 & -0.07 & $-0.26^{* *}$ & -0.12 & -0.09 & -0.07 & -0.01 \\
\hline
\end{tabular}

Note. ISO = Instability of the Self and Others; IB = Instability of Behavior; IG = Instability of Goals; PSI = Psychosis; SDA = Self-Directed Aggressiveness; DMV = Distortion of Moral Values; SA = Sadistic Aggression.

$* p<.05 ; * * p<.01$.

Table 3

Standardized Beta Coefficients of the Linear Regression Models

\begin{tabular}{|c|c|c|c|c|c|c|c|}
\hline & ISO & IB & $\mathrm{IG}$ & PSI & $\mathrm{SDA}$ & DMV & SA \\
\hline$R^{2}$ & 0.68 & 0.59 & 0.27 & 0.43 & 0.47 & 0.42 & 0.42 \\
\hline $\mathrm{F}$ & 23.17 & 15.69 & 4.52 & 9.03 & 10.82 & 8.15 & 8.68 \\
\hline Vulnerability (N1) & $0.28 * * *$ & $0.19 *$ & 0.10 & 0.10 & -0.02 & $0.22 *$ & 0.02 \\
\hline Instability (N2) & 0.12 & $0.22 * *$ & 0.11 & $0.17 *$ & $0.16^{*}$ & 0.15 & 0.05 \\
\hline Passivity (N3) & -0.08 & -0.11 & 0.11 & -0.02 & $-0.35 * * *$ & -0.02 & 0.08 \\
\hline Depression (N4) & $0.28 * * *$ & $0.19 *$ & $0.06 * *$ & $0.28 * *$ & $0.39 * * *$ & 0.02 & $0.21 *$ \\
\hline Kindness (A1) & -- & -0.03 & 0.12 & -- & 0.02 & -0.13 & $-0.16^{*}$ \\
\hline Pro-Sociability (A2) & -0.03 & $-0.18 * *$ & $-0.19^{*}$ & -0.11 & $-0.26 * * *$ & $-0.15^{*}$ & $-0.24 * * *$ \\
\hline Trust in People (A3) & $-0.13^{*}$ & -0.11 & $0.08 * *$ & $-0.21 * *$ & 0.04 & $-0.18^{*}$ & $-0.15^{*}$ \\
\hline Competence (C1) & $-0.22 *$ & -0.04 & -- & -0.06 & $-0.27 *$ & -0.06 & 0.06 \\
\hline Weighting (C2) & $-0.12 *$ & $-0.14 * *$ & -- & $-0.22 * * *$ & -0.08 & -0.06 & $-0.15^{*}$ \\
\hline Engagement (C3) & $0.18 * *$ & -- & 0.01 & -- & -0.06 & -- & -- \\
\hline Level of Communication(E1) & 0.05 & -0.06 & -0.04 & -- & -- & 0.06 & -- \\
\hline Pride (E2) & $0.14^{*}$ & 0.15 & 0.04 & -0.12 & $0.18 *$ & 0.08 & 0.08 \\
\hline Dynamism (E3) & -0.02 & -0.05 & -- & $0.25 * *$ & 0.01 & -0.07 & 0.03 \\
\hline Social Interactions (E4) & -0.06 & -0.04 & -0.03 & -0.11 & -0.03 & -0.12 & -0.03 \\
\hline Openness to Ideas (O1) & 0.07 & 0.07 & -- & $0.24 * * *$ & -- & 0.06 & 0.08 \\
\hline Liberalism (O2) & -- & -- & 0.13 & -- & -- & -- & -- \\
\hline Search for Novelties (O3) & -- & -- & $0.19 * *$ & $-0.15^{*}$ & -- & -- & -- \\
\hline
\end{tabular}

Notes. (--) Facets that did not enter the regression analysis according to the exclusion criterion previously established for correlations with $p>.25$; All the models were significant with values $p \leq .001$ for the F-statistic of ANOVA; ISO = Instability of the Self and Others; IB = Instability of Behavior; IG = Instability of Goals; PSI = Psychosis; SDA = Self-Directed Aggressiveness; $\mathrm{DMV}=$ Distortion of Moral Values; $\mathrm{SA}=$ Sadistic Aggression.

$* p \leq .05 ; * * p \leq .01 ; * * * p \leq .001$. 
$(\beta=-0.14)$ facets were those that significantly contributed in the regression model. For the IG factor, the facets that presented explanatory power were Pro-sociability $(\beta=-0.19)$, Search for Novelties $(\beta=-0.19)$, Trust in People $(\beta=$ $0.08)$ and Depression $(\beta=0.06)$. In relation to the PSI factor, the Depression $(\beta=0.28)$, Dynamism $(\beta=0.25)$, Openness to Ideas $(\beta=0.24)$, Weighting $(\beta=-0.22)$, Trust in People $(\beta=$ $-0.21)$, Instability $(\beta=0.17)$ and Search for Novelties $(\beta=-0.15)$ facets presented explanatory power in the model.

In relation to the factors of the Additional Scales, it was observed that the variance of the SDA factor was significantly explained by the Depression $(\beta=0.39)$, Passivity $(\beta=-0.35)$, Competence $(\beta=-0.27)$, Pro-Sociability $(\beta=$
-0.26), Pride $(\beta=0.18)$ and Instability $(\beta=0.16)$ facets. The DMV factor, in turn, had the variance explained only by the Vulnerability $(\beta=$ $0.22)$, Trust in People $(\beta=-0.18)$ and Pro-Sociability $(\beta=-0.15)$. Finally, the SA factor had its variance explained by the Depression $(\beta=0.21)$, Kindness $(\beta=-0.16)$, Pro-sociability $(\beta=-0.24)$, Confidence in People $(\beta=-0.15)$ and Weighting $(\beta=-0.15)$ facets.

\section{Incremental Validity}

In order to evaluate the incremental validity of the IPO-Br, hierarchical regression analyses were conducted to verify the increment of information regarding the amount of psychopathological symptoms presented by the participants (dependent variable was the total SRQ-20 score). The results are shown in Table 4.

Table 4

Hierarchical Regressions Comparing the Contribution of IPO-Br and BFP Factors in Predicting the Severity of the SRQ-20 Symptoms

\begin{tabular}{|c|c|c|c|c|c|c|}
\hline \multicolumn{2}{|c|}{$\begin{array}{c}\text { Step 1: BFP } \\
\text { Step 2: IPO-Br }\end{array}$} & \multicolumn{2}{|c|}{$\begin{array}{l}\text { Step 1: IPO-Br } \\
\text { Step 2: BFP }\end{array}$} & \multirow[t]{2}{*}{ Total $R$} & \multirow[t]{2}{*}{ Adj. $R^{2}$} & \multirow[t]{2}{*}{ Significant predictors $(\beta)$ after Step 2} \\
\hline$R^{2}$ & $\Delta R^{2}$ & $R^{2}$ & $\Delta R^{2}$ & & & \\
\hline $0.51 * * *$ & $0.13 * * *$ & $0.52 * * *$ & $0.12 * * *$ & $0.64 * * *$ & $0.61 * * *$ & $\begin{array}{c}\text { Neuroticism }\left(0.38^{* * *}\right) \\
\text { Instability of the Self and Others }\left(0.25^{* *}\right) \\
\text { Self-Directed Aggressiveness }\left(0.24^{* *}\right) \\
\text { Sadistic Aggression }\left(-0.17^{*}\right) \\
\text { Extroversion }\left(-0.17^{* *}\right)\end{array}$ \\
\hline
\end{tabular}

Note. IPO-Br = Inventory of Personality Organization - Brazil; BFP = Factorial Personality Battery; SRQ-20 = Self-Reporting Questionnaire; Adj. $R^{2}=$ Adjusted $R^{2}$.

$* p \leq .05 ; * * p \leq .01 ; * * * p \leq .001$.

First, the big five personality factors were introduced (Step 1) followed by the introduction of the seven dimensions of personality functioning (measured by the IPO-Br). The results showed that the big five-factor model explained $51 \%$ of the SRQ-20 variance. After controlling the effect of the BFP, it was observed that the IPO-Br increased, in a statistically significant way, $13 \%$ of the explanation of the SRQ-20 variance. Thus, it was observed that the IPO$\mathrm{Br}$ factors increase the predictive power of the level of psychopathological symptomatology, in addition to the predictive power of the BFP factors. When inverting the order of inclusion of the variables into the model, similar values were observed for both the IPO-Br dimensions in the explanation of the SRQ-20 variance and for the BFP factors in the increment of this explanation. Therefore, there appears to be no substantial difference between the degree of increment of the IPO-Br and the BFP in explaining the variation in the amount of psychiatric symptoms of the participants. The factors that presented predictive power with statistical significance were: 
Neuroticism $(\beta=0.38)$, Instability of Self/Others $(\beta=0.25)$, Self-Directed Aggression $(\beta=0.24)$, Sadistic Aggression $(\beta=-0.17)$ and Extrover$\operatorname{sion}(\beta=-0.17)$.

\section{Discussion}

The present study aimed to investigate evidence of validity for the IPO-Br. As expected, it was observed that the pattern of correlations between the IPO-Br factors and the BFP dimensions is congruent with that indicated in the literature. Studies have shown that patients with personality disorders tend to have high levels of Neuroticism and low levels of Agreeableness, Conscientiousness and Extroversion (Amini et al., 2015; Laverdière et al., 2007; Malouff et al., 2005; Quilty et al., 2013; Reardon, Tackett, \& Lynam, 2017; Saulsman \& Page, 2004; Watson \& Naragon-Gainey, 2014; Widiger et al., 2002). Berghuis et al. (2009) drew special attention to the "NAC profile" (i.e., high traits of Neuroticism and low traits of Agreeableness and Conscientiousness). According to the authors, people with personality disorders tend to present this pattern of traits according to the big fivefactor model. The results of the present study were congruent with this profile, suggesting that the IPO-Br scales are measuring maladaptive characteristics of personality functioning, since, although the patients in the clinical sample did not necessarily have a nosological diagnosis of personality disorder, all of them presented some degree of impairment in their personality functioning.

The IG factor presented correlations only with the Neuroticism and Openness traits, with these being of weak magnitude, presenting an unexpected result for the associations between the IPO-Br and the big five-factor model. Among the factors related to the Primary Clinical Scales, this was the only one that did not present at least moderate magnitude correlations with Neuroticism, and weak magnitude correlations with Agreeableness. These results can be attributed to the fact that the IG factor is composed of only two items, which may represent a methodological bias. Nevertheless, this factor clearly emerged in the factorial structure and presented adequate internal consistency (Oliveira, 2016), similar to the factorial structure presented in the Ellison and Levy study (2012), suggesting that an alternative response to this question could be the elaboration of a greater number of items for the IG factor in future reformulations of the instrument.

The theoretical convergence indicated by the correlations between the Kernberg model and the big five-factor model was confirmed by the results of the regression analyses, carried out to deepen the understanding of the relationship between the models. The data indicated that individuals with impairments in the maintenance of a continuous experience of the self and instability in relationships with and perceptions of others (ISO) seem to present, in a more prominent way, characteristics such as experience of emotional suffering in relation to the acceptance of others and low self-esteem, expressed by the Vulnerability facet (Kernberg \& Caligor, 2005). The results also showed an association with loneliness, lack of clear goals for life and great perception about their value, indicated by the Depression and Pride facets. The association between ISO and the Trust in People indicates that discontinuity in the consistency of the self is also related to difficulty in believing in people (Horz-Sagstetter et al., 2017). The ISO was also negatively associated with all facets of Conscientiousness, indicating little motivation to deal with complex tasks and diffuse interest regarding the overall planning of their lives, which can lead to impairment in relationships (Jensen-Campbell \& Malcom, 2007; Nunes et al., 2010).

The IB factor regression model, which refers to impulsive behaviors and changes in behavior (Oliveira, 2016), showed a strong association with the Instability facet, which refers to take hasty decisions and to the tendency to act impulsively faced with some psychological discomfort (Critchfield et al., 2008). The factor was also associated with Vulnerability, suggesting that people with behavioral instability are more likely to be vulnerable and very dependent on the people closest to them. There was also 
an association with the Depression, given the relationship between maladaptive functioning and negative expectations regarding the future (Kernberg \& Caligor, 2005). The factor still had its variance explained by the Pro-Sociability and Weighting facets, indicating that instability of behavior is associated with risk behaviors, transgression of rules and impairment in the ability to evaluate the possible consequences of actions (Ucho, Terwase, \& Ucho, 2016).

The association of the IG factor with Trust in People, Depression, Pro-sociability and Search for Novelties suggests that people who find it difficult to establish goals in life demonstrate problems in trusting people, a high level of hopelessness, a tendency to expose themselves to risk situations and are easily bored when subjected to routines. Similar results were reported by Preti et al. (2015), where subjects with instability of goals presented great difficulty in assuming responsibilities.

The presence of psychotic experiences, such as hallucinations, delusions and mental confusion, described by the PSI factor, has been positively associated with the facets Depression, Instability, Dynamism and Openness to Ideas. Thus, people with unusual beliefs appear to have pessimistic expectations about the future, low tolerance for frustration and a preference to keep themselves occupied with varied activities. They also tend to show a tendency to participate in activities that involve the use of fantasy. These data are in agreement with previous research (Widiger et al., 2002), which describes high scores in Openness to Ideas in some psychopathological conditions, with difficulty in the maintenance of the test of reality, as in Schizotypal Personality Disorder. On the other hand, the negative association of PSI with Trust in People, Weighting and Search for Novelties indicates that people with psychotic characteristics may be more paranoid, having difficulty believing that people are well intentioned. In addition, they generally exercise little caution when expressing their opinions, because of the difficulties of assessing their feelings according to social norms (Caligor et al., 2007), and are resistant to following a routine.
Regarding the factors of the Additional Scales, it was observed that the SDA factor was related to feelings of having a monotonous and emotionless life, an unfavorable perception of oneself and disbelief regarding one's own ability (Critchfield et al., 2008; Di Pierro, Preti, Vurro, \& Madeddu, 2017), evidenced by the Depression and Competence facets. The factor was also related to the need to receive attention from people and the tendency to put oneself at risk, in association with the Pride and Pro-sociability facets. The DMV factor, in turn, presented a significant relationship with Vulnerability, Pro-sociability and Trust in People. These relationships show that poorly integrated and distorted aspects of morality are associated with excessive insecurity and dependence on close people, as well as manipulation and difficulty in trusting others (Critchfield et al., 2008). Finally, the SA factor, which involves heteroaggressiveness and the control and manipulation of others, has been associated with a hostile pattern of interaction, a negative perspective regarding the future, lack of empathy, absence of trust in others and an inability to evaluate consequences (Garcia-Sancho, Dhont, Salquero, \& Fernández-Berrocal, 2017; Ruiz \& Sánchez, 2008; Widiger et al., 2002).

Regarding the incremental validity, the results of the hierarchical regression analyses showed that the IPO-Br provides a significant contribution to the predictive power of psychological symptoms presented by the participants, overand above the factors of the BFP. This result adds new evidences of (incremental) validity to the instrument. In this sense, it was observed that more unstable characteristics, structural (ISO) or emotional (Neuroticism), are associated with a greater manifestation of psychiatric symptoms. In addition, the greater number of psychopathological symptoms tends to be more common in aggressive (SDA and SA) and introverted (Extroversion) people. In agreement with these findings, several studies have highlighted a positive relationship of symptoms of common mental disorders such as depression, anxiety disorders and psychosomatic 
symptoms with instability (Critchfield et al., 2008; Garcia-Sancho et al., 2017) and neuroticism (Lowyck et al., 2013; Malouff et al., 2005), as well as a negative association of extroversion with depressive symptoms, negative symptoms of schizophrenia and social anxiety (Watson \& Naragon-Gainey, 2014; Watson, Stasik, Ellickson-Larew, \& Stanton, 2015).

To conclude, the present study has some limitations, such as the reduced sample size and the fact that the sample was established by convenience, which partly limits the randomness and representativity of the sample in relation to the population. Thus, it is prudent that the results be understood as the phenomena of the sample studied. However, possible generalizations can also be considered, as the results were largely consistent with the literature.

In general, the present study contributes to the accumulation of evidence of validity of the IPO-Br in the Brazilian context. Six of the seven IPO-Br factors discriminated the groups of participants with and without clinical indicators. Only the DMV factor did not present a statistically significant difference between the groups. The observed convergences between the factors of the IPO-Br and those of the BFP indicate evidence of convergent validity for the instrument. Further to theoretically converging, the IPO-Br factors add predictive power, in addition to that provided by the BFP factors, to the identification of psychological malfunctioning. This result indicates evidence of incremental validity of the instrument. The results of the present study demonstrate the clinical value of the IPO-Br, as well as broaden the interpretations of its factors through associations with external measures.

\section{References}

Amini, M., Pourshahbaz, A., Mohammadkhani, P., Ardakani, M. R., Lotfi, M., \& Ramezani, M. A. (2015). The relationship between five-factor model and diagnostic and statistical manual of mental disorder-fifth edition personality traits on patients with antisocial personality disorder.
Journal of Research in Medical Sciences, 20(5), 470-476. Retrieved from https://www.ncbi.nlm. nih.gov/pmc/articles/PMC4590202/

Berghuis, H., Kamphuis, J. H., Boedijn, G., \& Verheul, R. (2009). Psychometric properties and validity of the Dutch Inventory of Personality Organization (IPO-NL). Bulletin of the Menninger Clinic, 73, 44-60. doi: 10.1521/ bumc.2009.73.1.44

Caligor, E., Kernberg, O. F., \& Clarkin, J. F. (2007). Handbook of dynamic psychotherapy for higher level personality pathology. Washington, DC: American Psychiatric Publishing.

Clarkin, J. F., Foelsch, P. A., \& Kernberg, O. F. (2001). The Inventory of Personality Organization (IPO). White Plains, NY: The New York Hospital-Cornell Medical Center. The Personality Disorders Institute, Department of Psychiatry, Weill College of Medicine of Cornell University. doi: 10.1037//1040-3590.13.4.577

Cohen, J., Cohen, P., West, S. G., \& Aiken, L. S. (2003). Applied Multiple Regression Analysis for the Behavioral Sciences ( $3^{\text {rd }}$ Ed.). Hoboken, NJ: Lawrence Erlbaum Associates.

Costa, P. T., Jr., \& Widiger, T. A. (2002). Introduction: Personality Disorders and the Five-Factor Model of Personality. In P. T. Costa \& T. A. Widiger (Eds.), Personality Disorders and the Five-Factor Model of Personality (pp. 3-14). Washington, DC: American Psychological Association.

Critchfield, K. L., Levy, K. N., Clarkin, J. F., \& Kernberg, O. F. (2008). The relational context of aggression in borderline personality disorder: Using adult attachment style to predict forms of hostility. Journal of Clinical Psychology, 64(1), 67-82. doi: 10.1002/jclp.20434

Dancey, C. P., \& Reidy, J. (2013). Estatística sem matemática para psicologia ( $5^{\text {th }}$ Ed.). Porto Alegre, RS: Penso.

Di Pierro, R., Preti, E., Vurro, N., \& Madeddu, F. (2014). Dimensions of personality structure among patients with substance use disorders and co-occurring personality disorders: A comparison with psychiatric out-patients and healthy controls. Comprehensive Psychiatry, 55, 13981404. doi: 10.1016/j.comppsych.2014.04.005

Ellison, W. D., \& Levy, K. N. (2012). Factor structure of the primary scales of the Inventory of Personality Organization in a nonclinical sample 
using exploratory structural equation modeling. Psychological Assessment, 24(2), 503-517. doi: 10.1037/a0026264

Ensink, K., Rousseau, M. E., Biberdzic, M., Bégin, M., \& Normardin, L. (2017). Reflective functioning and personality organization: Associations with negative maternal behaviors. Infant Mental Health Journal, 38(3), 351-362. doi: 10.1002/imhj.21643

Garcia-Sancho, E., Dhont, K., Salquero, J. M., \& Fernández-Berrocal, P. (2017). The personality basis of aggression: The mediating role of anger and the moderating role of emotional intelligence. Scandinavian Journal of Psychology. doi: 10.1111/sjop.12367

Goodman, G., Bartlett, R. C., \& Stroh, M. (2013). Mothers' borderline features and childrens' disorganized attachment representations as predictors of children's externalizing behavior. Psychoanalytic Psychology, 30(1), 16-36. doi: 10.1037/a0031068

Gonçalves, D. M., Stein, A. T., \& Kapczinski, F. (2008). Avaliação de desempenho do Self-Reporting Questionnaire como instrumento de rastreamento psiquiátrico: Um estudo comparativo com o Structured Clinical Interview for DSMIV-TR [Performance of the Self-Reporting Questionnaire as a psychiatric screening questionnaire: a comparativestudy with Structured Clinical Interview for DSM-IV-TR]. Cadernos de Saúde Pública, 24(2), 380-390. doi: 10.1590/ S0102-311X2008000200017

Hair, J. F., Jr., Black, W. C., Babin, B. J., Anderson, R. E., \& Tatham, R. L. (2009). Análise multivariada de dados. Porto Alegre, RS: Bookman.

Harding, T. W., De Arango, V., Baltazar, J., Climent, C. E., Ibrahim, H. H. A., Ladrido- Ignacio, L., \& Wig, N. N. (1980). Mental disorders in primary health care: A study of their frequency and diagnosis in four developing countries. Psychological Medicine, 10(2), 231-241. Retrieved from https://www.ncbi.nlm.nih.gov/pubmed/7384326

Heim, A., \& Westen, D. (2009). Theories of Personality and Personality Disorders. In J. M. Oldham, A. E. Skodol, \& D. S. Bender (Eds.). Essentials of personality disorders. Washington, DC: American Psychiatric Publications.

Hosmer, D. W., Jr., Lemeshow, S., \& Sturdivant, R. X. (2013). Applied logistic regression ( ${ }^{\text {rd }}$ Ed.). Hoboken, NJ: John Wiley \& Sons.
Horz-Sagstetter, S., Caligor, E., Preti, E., Stern, B. L., De Panfilis, C., \& Clarkin, J. F. (2017). Clinician-guided assessment of personality using the Structural Interview and the Structured Interview of Personality Organization (STIPO). Journal of Personality Assessment. doi: 10.1080/00223891.2017.1298115

Igarashi, H., Kikuchi, H., Kano, R., Mitoma, H., Shono, M., Hasui, C., \& Kitamura, T. (2009). The Inventory of Personality Organisation: Its psychometric properties among student and clinical populations in Japan. Annals of General Psychiatry, 8(9), 1-21. doi: 10.1186/1744-859X-8-9

Jensen-Campbell, L. A., \& Malcolm, K. T. (2007). The importance of conscientiousness in adolescent interpersonal relationships. Personality and Social Psychology Bulletin, 33(3), 368-383. doi: 10.1177/0146167206296104

Kernberg, O. F. (1995). Transtornos graves de personalidade. Porto Alegre, RS: Artes Médicas.

Kernberg, O. F. (2016). What is personality? Journal of Personality Disorders, 30(2), 145-156. Retrieved from http://guilfordjournals.com/doi/ pdf/10.1521/pedi.2106.30.2.145

Kernberg, O. F., \& Caligor, E. (2005). A Psychoanalytic Theory of Personality Disorders. In M. K. Lenzenweger \& J. F. Clarkin (Eds.), Major theories of personality disorder ( $2^{\text {nd }} \mathrm{Ed}$.). New York: The Guilford Press.

Laverdière, O., Gamache, D., Diguer, L., Hébert, É., Larochelle, S., \& Descôteaux, J. (2007). Personality organization, five-factor model, and mental health. The Journal of Nervous and Mental Disease, 195(10), 819-829. doi: 10.1097/ NMD.0b013e318156815d

Lenzenweger, M. F., Clarkin, J. F., Kernberg, O. F., $\&$ Foelsch, P. A. (2001). The Inventory of Personality Organization: Psychometric properties, factorial composition, and criterion relations with affect, aggressive dyscontrol, psychosis proneness, and self-domains in a nonclinical sample. Psychological Assessment, 13, 577-591. doi: $10.1037 / 1040-3590.13 .4 .577$

Lowyck, B., Luyten, P., Verhaest, Y., Vandeneede, B., \& Vermote, R. (2013). Levels of personality functioning and their association with clinical features and interpersonal functioning in patients with personality disorders. Journal of Personality Disorders, 27(3), 320-336. doi: 10.1521/pedi.2013.27.3.320 
Malouff, J. M., Thorsteinsson, E. B., \& Schutte, N. S. (2005). The relationship between the five-factor model of personality and symptoms of clinical disorders: A meta-analysis. Journal of Psychopathology and Behavioral Assessment, 27(2), 101-114. doi: 10.1007/s10862-005-5384-y

Millon, T. (2012). On the History and Future Study of Personality and Its Disorders. Annual Review of Clinical Psychology, 8(1-19). doi: 10.1146/ annurev-clinpsy-032511-143113

Normandin, L., Sabourin, S., Diguer, L., Dupont, G., Poitras, K., Foelsch, P., \& Clarkin, J. (2002). Évaluation de la validité théorique de l'Inventaire de l'organisation de la personnalité. Canadian Journal of Behavioural Science, 34(1), 5965. Retrieved from http://psycnet.apa.org/index. cfm?fa=buy.optionToBuy\&id=2002-00178-007

Nunes, C. H. S. S., Hutz, C. S., \& Nunes, M. F. O. (2010). Bateria Fatorial de Personalidade (BFP) - Manual técnico. São Paulo, SP: Casa do Psicólogo.

Oliveira, S. E. S. (2012). Diagnóstico estrutural da personalidade: Adaptação e validação do Inventory Personality Organization para a cultura brasileira (Unpublished master thesis, Instituto de Psicologia, Universidade Federal do Rio Grande do Sul, Porto Alegre, RS, Brazil).

Oliveira, S. E. S. (2016). Diagnóstico estrutural e dimensional da personalidade: Estudos psicométricos e de aplicação clínica (Unpublished doctoral dissertation, Instituto de Psicologia, Universidade Federal do Rio Grande do Sul, Porto Alegre, RS, Brazil).

Oliveira, S. E. S., \& Bandeira, D. R. (2011). Linguistic and cultural adaptation of the Inventory of Personality Organization (IPO) for the Brazilian culture. Journal of Depression \& Anxiety, 1(1), 1-7. doi: 10.4172/2167-1044.1000105

Pestana, M. H., \& Gagueiro, J. N. (2014). Análise de dados para ciências sociais $\left(6^{\text {th }}\right.$ Ed.). Lisboa: Síbalo.

Preti, E., Prunas, A., De Panfilis, C., Marchesi, C., Madeddu, F., \& Clarkin, J. F. (2015). The facets of identity: Personality pathology assessment through the Inventory of Personality Organization. Personality Disorders: Theory, Research, and Treatment, 6(2), 129-140. doi: 10.1037/ per0000119

Quilty, L. C., Ayearst, L., Chmielewski, M., Pollock, B. G., \& Bagby, R. M. (2013). The psy- chometric properties of the Personality Inventory for DSM-5 in an APA DSM-5 field trial sample. Assessment, 20(3), 362-369. doi: $10.1177 / 1073191113486183$

Reardon, K., Tackett, J., \& Lynam, D. (2017). The personality context of relational agression: A five-factor model profile analysis. Personality Disorders. doi: 10.1037/per0000231

Ruiz, L. R., \& Sánchez, A. R. R. (2008). Description of the structural organization of the personality in adolescents who studied first semester in a psychology program in the city of Barranquillla. Psychologia: Avances de la Disciplina, 2, 65-91. Retrieved from http://www.redalyc.org/ pdf/2972/297225162002.pdf

Saulsman, L. M., \& Page, A. C. (2004). The fivefactor model and personality disorder empirical literature: A meta-analytic review. Clinical Psychology Review, 23, 1055-1085. doi: 10.1016/j. cpr.2002.09.001

Smits, D. J., Vermote, R., Claes, L., \& Vertommen, H. (2009). The Inventory of Personality Organization-Revised: Construction of a bridged version. European Journal of Psychological Assessment, 25, 223-230. doi: 10.1027/1015-5759.25.4.223

Verreault, M., Sabourin, S., Lussier, Y., Normandin, L., \& Clarkin, J. F. (2013). Assessment of personality organization in couple relationships: Factorial structure of the inventory of personality organization and incremental validity over neuroticism. Journal of Personality Assessment, 95(1), 85-95. doi: $10.1080 / 00223891.2012 .713883$

Ucho, A., Terwase, J. M., \& Ucho, A. A. (2016). Influence of Big Five Personality Traits and Locus of Control on Road Safety Rules Compliance among Motorcycle Riders in North-Central Nigeria. Asia Pacific Journal of Education, Arts and Sciences, 3(1), 1-9. Retrieved from http:// apjeas.apjmr.com/wp-content/uploads/2016/01/ APJEAS-2016.3.1.01.pdf

Watson, D., \& Naragon-Gainey, K. (2014). Personality, emotions, and the emotional disorders. Clinical Psychological Science, 2, 422-442. doi: $10.1177 / 2167702614536162$

Watson, D. Stasik, S. M., Ellickson-Larew, S., \& Stanton, K. (2015). Extraversion and psychopathology: A facet-level analysis. Journal of Abnomal Psychology, 124(2), 432-446. doi: 10. 101037/abn0000051 
Widiger, T., Trull, T., Clarkin, J., Sanderson, C., \& Costa, P., Jr. (2002). A description of the DSMIII-R and DSM-IV personality disorders with the five-factor model of personality. In P. T. Costa Jr. \& T. A. Widiger (Eds.), Personality disorders and the five-factor model of personality (pp. 41-56). Washington, DC: American Psychological Association.

Zimmermann, J., Benecke, C., Hörz, S., Rentrop, M., Peham, D., Bock, A., ...Dammann, G. (2013). Validierung einer deutschsprachigen 16-Item-
Version des Inventars der Persön lichkeitsorganisation (IPO-16). Diagnostica, 59, 3-16. doi: 10.1026/0012-1924/a000076

Received: 09/11/2017

$1^{\text {st }}$ revision: $22 / 02 / 2018$

Accepted: 25/02/2018 distribution, and reproduction in any medium, provided you give appropriate credit to the original author(s) and the source, provide a link to the Creative Commons license, and indicate if changes were made. 